\title{
CUA guideline on the care of the normal foreskin and neonatal circumcision in Canadian infants (abridged version)
}

\author{
Sumit Dave ${ }^{1}$; Kourosh Afshar ${ }^{2}$; Luis H. Braga ${ }^{3}$; Peter Anderson ${ }^{4}$ \\ ${ }^{1}$ Department of Surgery (Urology), Western University, London, ON; ${ }^{2}$ Department of Urologic Sciences, \\ University of British Columbia, Vancouver, BC; ${ }^{3}$ Department of Surgery (Urology), McMaster University, \\ Hamilton, ON; ${ }^{4}$ Department of Urology, Dalhousie University, Halifax, NS; Canada
}

Cite as: Can Urol Assoc J 2017 Dec. 1; Epub ahead of print. http://dx.doi.org/10.5489/cuaj.5034

Published online December 1, 2017

$* * *$

\section{Introduction}

Circumcision is the oldest planned operative procedure in the history of the human civilization, but there continues to be a lack of consensus and strong opposing views on whether universal neonatal circumcision should be adopted as a public health measure. The American Academy of Pediatrics 2012 guideline on male circumcision (MC), reversed its prior stand stating that the "health benefits of newborn male circumcision outweigh the risks" and justify access to the procedure if the parents so choose ${ }^{1}$. The following set of guidelines will investigate and provide evidence regarding the benefits of neonatal MC, its potential complications and the care of the normal foreskin in early childhood, adapted for the Canadian population and health care system. A more comprehensive version of this guideline describing the detailed evidence to support the proposed recommendations and including sections on $\mathrm{MC}$ trends, indications of pediatric MC, cost analyses and training implications is provided in the web version of this guideline (available at cuaj.ca). The evidence presented is classified according to the

Oxford system of evidence-based medicine, with a summary using the GRADE system ${ }^{2}$.

\section{Methods}

Systematic literature searches were conducted in MEDLINE including Pre-MEDLINE EMBASE, BIOSIS Previews ${ }^{\circledR}$, Web of Science ${ }^{\circledR}$ - with Conference Proceedings, and the Cochrane Central Register of Controlled Trials electronic bibliographic databases and were restricted to either adult or pediatric studies ( $</>18$ years) (January 2000 to March 2013). An additional limited review was conducted till June 2016 to include any subsequent significant studies. All searches were restricted to studies published in the English language. The search strategy is described in the web version of the guideline. After excluding duplicate records and non-relevant studies, a total of 233 studies out of 
2674 were included in this analysis, though some studies are only discussed in the detailed version of this guideline.

Care of the normal foreskin in childhood and management of physiological phimosis The prepuce arises from the coronal margin by a combination of folding and epithelial outgrowth and has an outer and inner layer separated by Dartos fascia. At birth, the inner foreskin is fused to the glans penis and should not be retracted until spontaneous retraction occurs over the first few years of life. In the absence of clinical scarring suggesting pathological phimosis (Fig. 1), history of recurrent urinary tract infections (UTI's) or balano-posthitis (Fig. 2), no intervention is required for physiological phimosis. Ballooning of the foreskin during voiding is not associated with obstructed voiding and is not an indication for circumcision ${ }^{3}$. Vigorous retraction has the potential to cause micro-tears leading to scarring and an iatrogenic true phimosis. Therefore, normal foreskin care in early childhood starts once the foreskin is retractable and this occurs at varying ages. Indications for urological consultation include suspicion of true phimosis with evident scarring, Lichen sclerosis of the foreskin (Fig. 3), recurrent episodes of balano-posthitis or recurrent UTI's, and delayed retraction of the foreskin past 8-10 years of age ${ }^{4}$.

\section{Treatment of physiological phimosis}

Several observational studies and randomized trials have investigated the role of topical steroids and preputial stretching in resolving physiologic phimosis. A recent metaanalysis and several RCT's show significant success (60-80\%) when using topical steroid creams as a treatment modality for physiological phimosis ${ }^{5-9}$. Success rates are not dependent on steroid potency ${ }^{10}$. Side effects are rare and there was no suppression of the hypothalamic-pituitary-adrenal axis provided therapy was limited to 8 weeks for each course ${ }^{11}$. Success with this treatment modality, lies in differentiating physiologic and true phimosis, active counseling and selecting patients when they are age-appropriate to attempt this treatment modality. Physiological phimosis does not require treatment unless the child has recurrent UTI's or balano-posthitis. In some instances, in an older prepubertal child, topical steroid therapy can be initiated for persisting physiological phimosis ${ }^{4}$.

Recommendations (care of the normal foreskin and physiological phimosis):

1. Neonatal examination of the foreskin and urethral meatus should be part of routine clinical assessment of all newborn boys. Continued examination of the foreskin, without forcible retraction, is recommended during yearly physical examinations to rule out pathological phimosis and document natural preputial retraction (Level 5, Grade D). 
2. Persistent physiological phimosis in the absence of recurrent balanoposthitis or UTI's is not an indication for circumcision [Level 5, Grade D].

3. Topical steroids are the first line of treatment for physiological phimosis with good success rates and low risk of complications (Level 1b/2b, Grade A).

4. Moderately- low potency steroids (triamcinolone, clobetasone, hydrocortisone, mometasone) have similar success compared to a highly potent steroid (betamethasone) (Level 2b, Grade B).

5. Patient selection to ensure compliance, demonstrating the technique of steroid application and retraction and continued retraction after initial success is important to achieve success following topical steroid therapy for physiological phimosis (Level 5 Grade D).

6. Recurrence of physiological phimosis is common if retraction is not carried out after initial success and a repeat course of topical steroid therapy is recommended (Level $2 \mathrm{~b} / 3$ Grade $\mathrm{C}$ ).

\section{Circumcision and risk of urinary tract infections}

Prior evidence indicates that neonatal MC decreases the risk of UTI's ${ }^{12}$, but there is ongoing debate on the magnitude and duration of this effect. The role of circumcision in preventing UTI's must be studied in 2 distinct subgroups: males with normal urinary tracts and those with recurrent UTI's or urological conditions predisposing to UTI's like antenatal hydronephrosis, vesico-ureteric reflux (VUR), posterior urethral valves, neurogenic bladders and primary megaureters. In boys without predisposing urological conditions, the estimated incidence of UTI in the first 10 years of life varies between 1 to $2 \%{ }^{12,13}$. In a meta-analysis of febrile infants (males and females 0-24 months), Shaikh et al estimated the prevalence of UTI was $7 \%$, with males under 3 months having the highest prevalence ${ }^{14}$.

Boys with normal urinary tracts

Previous studies have shown that the risk of UTIs is increased in uncircumcised males ${ }^{13}$, 15-21. In a case-control study from Australia which included children with urological abnormalities, Craig et al showed that the protective effects of MC in infants, was marginally significant (OR 0.03 95\% CI 0.06-1.1). However, this effect was not observed beyond infancy (OR=0.2, 95\% CI 0.01-3.7) ${ }^{21}$. A systematic review (SR) by SinghGrewal supported the beneficial effects of MC on pediatric UTI risk (OR 0.13 95\% CI $0.07-0.23){ }^{16}$. Assuming a $1-2 \%$ circumcision complication rate and a $1 \%$ UTI risk in normal infants, universal neonatal circumcision is hard to justify based on a number needed to treat (NNT) of $111^{16}$. Even if we accept a lower complication rate of $0.2 \%$ and a $2 \%$ UTI risk, given the effectiveness of UTI treatment, 6 UTI's will be prevented at the 
expense of $1 \mathrm{MC}$ complication. A recent SR conducted by Morris et al, calculated the lifetime risk of a UTI to be $32 \%$ in uncircumcised males compared to $9 \%$ in circumcised males $^{22}$. The authors suggested a lower NNT of 4.2 (95\% CI 2.2-27) for preventing 1 UTI, albeit, over a lifetime.

\section{Boys with abnormal urinary tract}

In urological conditions like high grade VUR, posterior urethral valves, primary megaureters the risk of UTI is higher. In patients with VUR, circumcision was more effective than antibiotic prophylaxis alone or surgical correction in preventing UTIs and the occurrence of new DMSA abnormalities ${ }^{23-25}$. Similar results were seen in boys with posterior urethral valves ${ }^{26}$ and infants with significant antenatal hydronephrosis ${ }^{27}$. In this subset of boys, with a risk of recurrent UTI (assuming 10\% UTI risk, the NNT is 11) and for boys with urological abnormalities (assuming 30\% UTI risk high grade VUR, the NNT is 4), a circumcision should be considered ${ }^{16}$. Topical steroid treatment of physiological phimosis to allow retraction and hygiene or antibiotic prophylaxis are other viable options for these children.

\section{Recommendations (circumcision and UTIs):}

1. Neonatal circumcision decreases the risk of UTI during early childhood (Level 2a) but the overall risk of UTI is low in infant males beyond 3 months of life and decreases further beyond infancy (Level 2b-4).

2. There is paucity of level-1 evidence to justify recommending universal neonatal circumcision to prevent UTI's in normal males.

3. A stronger effect of neonatal circumcision in preventing UTI's in boys with posterior urethral valves and significant antenatally detected hydronephrosis has been demonstrated and therefore it is recommended that a discussion regarding $\mathrm{MC}$ with the parents is advisable for these neonates (Level 3-4 Grade C).

Circumcision and risk of sexually transmitted infections

A decreased risk of Human immunodeficiency virus (HIV) and other sexually transmitted infections (STI's) is the primary argument driving a change in risk-benefit assessment of MC.

\section{Human immunodeficiency virus (HIV)}

A recent Public Health Agency of Canada reported an estimated HIV prevalence rate of 208 per 100,000 population, with an 11.4\% increase compared to 2008 estimates ${ }^{28}$. Men who have sex with men (MSM) accounted for $47 \%$ of prevalent infections followed by intra-venous drug users (17\%) and heterosexual individuals (17.6\%). 
Based on RCT's conducted in high HIV prevalence sub-Saharan Africa, there is clear Level 1 evidence that MC reduces the risk of HIV infection in heterosexual men (Table 1) ${ }^{29-31}$. In 2007, the WHO and UNAIDS recommended MC in HIV prevalent areas in combination with the promotion of "ABC" (Abstinence, Behavior change and correct and consistent Condom use) ${ }^{29}$. The protective effect of circumcision against HIV infection has been attributed to decreased coital trauma, decreases in prevalence of Langerhans cells, as well as increased keratinization of the glans ${ }^{32-34}$.

\section{Female to male HIV transmission}

Several RCT's and a meta-analysis of 15 observational studies conducted in 2000, supported a protective effect of MC against HIV infection (adjusted RR 0.42, 95\% CI 0.34-0.54\%) ${ }^{29-31,35,36}$. A Cochrane review of the 3 African trials supported the finding that MC is protective against female to male HIV transmission (IRR 0.5, 95\% CI 0.340.72 at 1 year and IRR 0.46 , 95\% CI $0.34-0.62$ at 2 years) ${ }^{36}$.

\section{Male to male HIV transmission}

Evidence of an association between circumcision status and HIV infection in men who have sex with men (MSM) is limited to observational studies, often not stratified by receptive and insertive roles. It is believed that men who practice an insertive role could likely benefit from $\mathrm{MC}$ while those who perform a receptive role may have little or no protection. In a Cochrane review by Wiysonge et al (6 cohort, 14 cross-sectional, 1 casecontrol; 71,693 participants), risk for HIV acquisition in MSM males was not altered by MC (OR 0.86, 95\% CI 0.7-1.06) ${ }^{37}$. In a subgroup analysis of men reporting an insertive role, MC was found to be protective (OR 0.27, 95\% CI 0.17-0.44). A previous metaanalysis by Millett et al in 2008, similarly concluded that MC is not protective against MSM HIV transmission ${ }^{38}$.

\section{Male to female HIV transmission}

MC can potentially decrease female partner HIV infection directly or indirectly by reducing overall male prevalence of HIV at the population level. However, a Ugandan RCT and a MA of observational studies found that MC did not provide any protective effects against male to female HIV transmission ${ }^{39,40}$.

Several factors need to be considered to make appropriate recommendations for our population. The MC rate in the 3 African countries ranged between 10-20\% and HIV prevalence was between $7-25 \%$. In contrast, the Canadian MC rate is around $35-40 \%$ and HIV prevalence is much lower leading to a potentially higher NNT. In addition, in Canada, only a small proportion of HIV transmission is attributed to heterosexual activity, and evidence suggests that MSM men are not protected by MC. Variations in sexual practices, education, behavior (condom usage), differences in STI prevalence and access to health care, are likely to modify the magnitude of the protective effects. In 
addition, the long- term effectiveness of MC beyond 2 years is available only for the Ugandan trial $^{41}$. The possibility of behavioral disinhibition, leading to unsafe sexual practices, which can potentially offset the protective effect of MC has been documented in several follow-up studies of the African RCT's ${ }^{41,42}$.

Recommendations (circumcision and HIV):

1. Female to male transmission: There is compelling evidence that MC reduces the risk of HIV transmission from female partners to male (Level 1 A evidence, Grade A recommendation). The magnitude of the effect may not be similar to the African trials in Canada and is not established for neonatal MC.

2. Male to male transmission: Based on current evidence, MC does not provide protection for men who have sex with men (Level 2a evidence).

3. Women partners: Based on current evidence, $\mathrm{MC}$ is not protective for female partners (Level 2a-b evidence).

4. Based on current evidence, universal neonatal circumcision cannot be recommended to prevent HIV infection (Grade B).

\section{Human papilloma virus (HPV)}

Human papilloma virus (HPV) is the most common STI worldwide and up to $75 \%$ of Canadians will have at least one lifetime HPV infection. The effect of MC on HPV is difficult to interpret as HPV infection can be transient and can affect multiple genital areas. In addition, HPV prevalence, incidence, clearance and viral load are all potential outcomes with differing health implications.

\section{HPV in men}

Two meta-analyses were conducted evaluating the effect of MC on HPV ${ }^{43,44}$. Albero et al analyzed data from 14 observational studies and 2 RCTs ${ }^{44}$. Accepting heterogeneity, data from the 2 RCT's, showed a strong inverse association between MC and high-risk HPV prevalence (OR 0.67, 95\% CI 0.54-0.82). The 14 prevalence studies showed a similar pooled result of HPV prevalence. There was no association between MC and incident HPV infections or clearance. A previous MA conducted by Larke et al, also showed similar prevalence results (OR 0.57, 95\% CI 0.45-0.71) ${ }^{43}$. There was weak evidence that MC was associated with decreased HPV incidence (RR 0.75, 95\% CI 0.570.99) or clearance (RR 1.33, 95\% CI 0.89-1.98).

\section{HPV in female partners}

Two trials conducted on HIV positive and negative men in Uganda analyzed transmission of HPV to female partners ${ }^{45,46}$. In the first trial on HIV negative men, the prevalence of HR-HPV infection in female partners was lower in the circumcised group (PRR 0.72, 
95\% CI 0.60-0.85) ${ }^{45}$. The clearance rate for all genotypes (except HPV 16) was improved in females with circumcised partners $(\mathrm{p}=0.014)$. In a second trial on female partners of HIV infected men, Tobian et al showed that MC was not associated with lower HR-HPV prevalence (PRR=1.07, 95\% CI 0.86-1.32) ${ }^{46}$.

The benefits of MC on HPV prevalence and incidence has to be balanced against the effectiveness of condom usage and HPV vaccination ${ }^{47,48}$.

\section{Recommendations (circumcision and HPV):}

1. HPV prevalence in men: Current evidence suggests a modest decrease in HPV prevalence in the glans and coronal sulcus up to 2 years following MC. (Level $1 b$ evidence). The protective effect is partial, does not cover all high- risk types and is weaker further away from the glans and coronal sulcus. It is not clear whether this effect will persist into adulthood following neonatal circumcision.

2. HPV clearance in men: There is no evidence (except a single RCT on HIV negative men) that MC increases HPV clearance (Level 1b-2b evidence). Theoretically, if MC increases clearance this may also inflate the impact on HPV prevalence.

3. HPV incidence or acquisition in men: There is no convincing evidence to suggest that MC decreases HPV acquisition or affects HPV incidence in HIV positive or negative men (Level $1 \mathrm{~b}-2 \mathrm{~b}$ evidence).

4. HPV in female partners: MC possibly lowers prevalence, incidence and clearance in female partners of HIV negative men (Level 1b-2b).

5. As a public health intervention, universal neonatal MC is not justifiable given access to HPV vaccination and baseline socio-economic and educational status (Grade B).

3. Non-ulcerative STIs, genital ulcer disease (GUD), and ulcerative STIs The most common non- ulcerative STIs are Gonorrhea, Chlamydia and Trichomonas infections. 2 RCT's have addressed the role of MC in these infections ${ }^{49}{ }^{50}$. In the Kenyan study, there was no association between MC and non-ulcerative STIs (HR 0.64, 95\% CI 0.50-0.82), though condom usage was protective ${ }^{49}$. The South African trial showed lower Trichomonas vaginalis infection in men in an as-treated analysis (Adjusted OR $0.47,95 \%$ CI $0.25-0.92)^{50}$. A MA of 30 observational studies failed to identify a statistically significant association between non- ulcerative STI's and MC ${ }^{51}$. In another prospective study, uncircumcised male partners had a higher risk of $\mathrm{T}$. vaginalis infection compared to circumcised partners of T. vaginalis infected women (OR 1.8, 95\% CI 1.1$3.2)^{52}$. In a prospective cohort study, MC did not have any protective effect on female partners with regards to chlamydial, gonococcal and trichomonal infections ${ }^{53}$. 
Herpes simplex virus (HSV), $T$ pallidum (syphilis), $H$ ducreyi (chancroid) and $K$ granulomatis (Donovanosis) are the common causes of genital ulcer disease (GUD). Women and men with GUD and HSV-2 have a higher risk of acquiring or transmitting HIV and conversely HIV infection increases the risk of GUD ${ }^{54,55}$. In a MA of observational studies, MC was not associated with a decreased risk of HSV-2 seropositivity (RR 0.88, 95\% CI 0.77-1.01) ${ }^{56}$. There was a protective effect of MC on syphilis seropositivity (RR 0.67, 95\% CI 0.54-0.83) and the results for chancroid infections was unclear. In HIV positive men, Tobian et al showed a lower risk of HSV 2 seroconversion in the circumcised group (Adjusted IRR 0.70, 95\% CI 0.55-0.91) ${ }^{57}$. Consistent condom usage had a slightly higher protective effect. In HIV negative men, the partial protective effect of MC against HSV-2 seroconversion was similar ${ }^{58}$.

Multivariate analysis of South African RCT data, did not show a protective effect of MC against HSV-2 seroincidence (IRR 0.68, 95\% CI 0.38-1.22) ${ }^{59}$. Mehta et al conducted an RCT in Kenya and observed that HSV-2 incidence did not differ by circumcision status ( $R R=0.94,95 \%$ CI 0.7-1.25) but HSV-2 incident infection tripled the risk of HIV acquisition ${ }^{60}$.

\section{Male to male HSV-2 transmission}

In a Cochrane review of MSM males, MC did not have a protective role in preventing syphilis (OR 0.96, 95\% CI 0.82-1.13) or HSV-2 infections (OR 0.86, 95\% CI 0.621.21) ${ }^{61}$.

Non-ulcerative and ulcerative STIs in female partners

Gray et al followed HIV negative women married to men randomized to circumcised and non-circumcised groups ${ }^{62}$. Adjusted analyses suggested a $22 \%$ circumcision efficacy for GUD (95\% CI 0.61-0.99), a 45\% efficacy for trichomonas (95\% CI 0.34-0.89) and a 18\% efficacy for bacterial vaginosis (95\% CI 0.74-0.91). In the Ugandan RCT on HIV negative men, MC did not reduce the risk of HSV-2 acquisition in women partners ${ }^{63}$.

\section{Recommendations (circumcision and ulcerative/ non-ulcerative STIs):}

1. Currently, there is no significant evidence to support the protective role of MC in the acquisition of non-ulcerative STIs, though there may be a protective effect on acquisition of Trichomonas infections (Level 2a-b evidence, Grade B recommendation).

2. Currently, there is no significant evidence to support the protective role of MC for males and females in the acquisition of ulcerative STI's (Level 2-4 evidence, Grade $C$ recommendation).

3. There is weak evidence of a partial protective effect of MC against HSV-2 infections in adult men following MC (Level 2a-b).

\section{Circumcision and penile cancer}


In a MA of 8 studies, Larke et al showed that $\mathrm{MC}<18$ years of age was protective against invasive penile cancer (OR 0.33, 95\% CI 0.13-0.83) ${ }^{64}$. In a matched case control study, Tsen et al showed that phimosis was a strong risk factor for invasive penile cancer ${ }^{65}$. The protective effect of neonatal MC was not statistically significant when the analysis was restricted to those who did not have a history of phimosis (OR 0.79, 95\% CI 0.29-2.6). In another case control study from Denmark, penile cancer was associated with phimosis (OR 4.9, 95\% CI 1.85- 13.0), but not childhood circumcision $(\mathrm{p}=0.33)^{66}$. Daling et al also showed that after excluding patients with phimosis, lack of childhood MC was not a risk factor for penile cancer ${ }^{67}$. Penile cancer is strongly associated with other risk factors like smoking, sexual practices and HPV infection, which can be modified as opposed to universal MC ${ }^{68}$.

Recommendations (circumcision and penile cancer):

1. Circumcision decreases the risk of penile cancer (Level 2-3).

2. However, given the low incidence of invasive penile cancer, the partial protective effect of MC, and the availability of other preventive strategies like HPV vaccination, condom usage and smoking cessation programs, it is difficult to justify universal neonatal circumcision as a preventive strategy for preventing penile cancer (Grade B).

3. Recognition and treatment of phimosis during regular health visits is recommended to decrease the risk of penile cancer (Level 5, Grade D). A genitourinary exam during puberty is recommended to ensure preputial retractability and hygiene, and counsel regarding HPV vaccination and safe sexual practices (Grade $D$ ).

\section{Circumcision and prostate cancer}

A recent case control study showed no protective effect of MC on prostate cancer (OR 0.87, 95\% CI 0.74-1.02) ${ }^{69}$. Another population-based study from Montreal also demonstrated no significant overall protective effect of MC (or infant MC), but the results where significant for men circumcised at $\geq 36$ years of age (OR 0.55, 95\% CI 0.30, $0.98){ }^{70}$. A UK study did not find any significant correlation between MC and prostate cancer $^{71}$. 


\section{Recommendations (circumcision and prostate cancer):}

1. There is no convincing evidence to suggest any protective effect of MC against prostate cancer (Level 3- 4 evidence, Grade B).

\section{Role of the foreskin in sensation and sexual function}

There is ongoing controversy regarding the impact of circumcision on penile sensitivity and sexual satisfaction. The primary question is whether loss of sensory nerves in the foreskin or a possible decrease in glans sensitivity impacts sexual satisfaction, after accounting for several confounders.

A recent meta-analysis included 10 studies to assess the impact of MC on sexual function ${ }^{72}$. There were no significant differences in sexual desire, dyspareunia, premature ejaculation, ejaculation latency time or erectile dysfunctions between circumcised and uncircumcised men. A secondary analysis of the Ugandan RCT showed no long term differences in 4456 men for sexual desire, satisfaction and erectile dysfunction ${ }^{73}$. A similar trial from Kenya found contradictory results where uncircumcised men reported an increase in sexual satisfaction ${ }^{74}$. Intravaginal ejaculation latency time (IELT) measured in a multinational study using a stopwatch and a blinded timer showed that MC and condom use did not impact IELT ${ }^{75}$.

\section{Sexual function in partners}

In an analysis of self-reported sexual experience in women partners of men before and after circumcision, Kigozi et al showed no changes in 57\% and improved sexual satisfaction in $40 \%{ }^{73}$. In a study comparing uncircumcised and circumcised homosexual men, Mao et al noted no differences in sexual difficulties or type of anal sex practiced ${ }^{76}$.

\section{Conclusions (circumcision and sexual function):}

- There is lack of convincing evidence that adult male circumcision impacts sexual function (Level 3-4 evidence, Grade C recommendation).

\section{Contraindications of neonatal circumcision}

Neonatal circumcision should be performed on stable infants who do not have associated congenital anomalies of the penis (Figs. 4-9). In some off these conditions, MC can be performed with appropriate technical modifications. Children with blood dyscrasias can undergo MC, after appropriate treatment ${ }^{77}$.

\section{Anesthesia for neonatal circumcision}

It is clear that neonatal circumcision must be performed with adequate anesthesia and analgesia ${ }^{78,79}$. The adverse physiological and behavioral responses of inadequate pain control in neonates is convincing, can lead to potential complications and alter long-term pain responses in the neonate. Different methods used for providing anesthesia and/or 
analgesia during circumcision includes general anesthesia, topical anesthetics, penile nerve blocks, oral sucrose-glucose administration, non-nutritive sucking, caudal block and various combinations of the above ${ }^{78,79}$.

The 3 topical anesthetic options currently available include; lidocaine-prilocaine 5\% cream (EMLA), tetracaine 4\% gel and liposomal lidocaine 4\% cream. Dorsal penile (DPNB) and ring blocks are effective techniques to manage circumcision related pain. Based on the Cochrane review by Brady-Fryer, a dorsal penile nerve block is the most effective intervention for circumcision related pain with the caveat that the injection is performed appropriately ${ }^{78}$. Oral administration of sucrose, glucose, or parenteral acetaminophen are not sufficient as sole measures for relieving the pain associated with circumcision $^{78,78,80}$.

Recommendations for anesthesia and analgesia for neonatal circumcision:

1. A dorsal penile nerve block with a ring block, using proper technique, is the most effective technique to provide anesthesia during a neonatal circumcision (Level 1-2 evidence, Grade A recommendation).

2. Topical local anesthetics alone are inferior to nerve and ring blocks and require an adequate time interval for efficacy and can be used as an adjunct to penile blocks (Level 1-2 evidence, Grade A recommendation).

3. Oral sucrose, non- nutritive sucking, music and other environmental interventions should only be used as an adjunct to the above methods (Level 1-3 evidence, Grade A recommendation).

\section{Complications of circumcision}

Neonatal circumcision is a safe surgical procedure and complications vary depending on surgeon experience, technique used, age at MC, anatomic factors and the accuracy and degree of post-operative reporting. Proper pre-operative assessment to recognize possible complicating anatomic factors (penoscrotal webbing, ventral skin deficiency, suprapubic fat pad) and adequate post-operative instructions to ensure retraction of the residual shaft skin can prevent most complications.

\section{Overall complication rates}

Several studies have investigated the complication rates of neonatal MC ${ }^{81-86}$. A recent SR on complications of neonatal MC noted a wide $0-16 \%$ (median $2 \%$ ) range of adverse events in 16 prospective studies ${ }^{81}$. The previous AAP Task Force on Circumcision reported a complication rate of $0.2-0.6 \%{ }^{83}$, while the Canadian Pediatric Society published complication rates as high as $2 \%{ }^{84}$.

Post-circumcision complications can be divided into early and late complications ${ }^{81-87}$. Early complications include bleeding, infection, glans necrosis/amputation, delayed or early slippage of circumcision devices and very rarely 
death. Late complications include inadequate skin removal, inclusion cysts, adhesions and skin bridges, suture sinus tracts, ventral curvature, secondary buried penis and phimosis, urethro-cutaneous fistulae and meatal stenosis ${ }^{87}$.

\section{Conclusions regarding circumcision complications:}

1. Complication rates following neonatal MC range between $0.6-2 \%$, depending on accuracy of reporting. Given the variability in complication rates and risk of delayed complications, the overall complication rate for neonatal MC may be higher than quoted in the literature (Level 2-4).

2. Operator experience, recognition of contraindications to MC, technique used, age and patient related variables can potentially impact complication rates [Level 4, Grade D].

\section{Summary of results and recommendations}

The benefits of neonatal MC have to be analyzed at the individual and societal level and be objectively balanced against the complication rates, healthcare costs and implications to our healthcare system. For a minority of Canadian neonates, there are well defined advantages of a circumcision but the magnitude of these benefits is not clearly defined. In addition, the protective benefits of MC are not comprehensive, may not last over a lifetime and can be achieved by other preventive health measures, which do not involve a surgical procedure.

The GRADE system is an appropriate method to employ when the evidence is variable in quality and generalizability ${ }^{2}$. We did not perform a GRADE effects calculation analyses for our outcomes but used the methodology to objectively classify the quality of evidence we present to support our recommendations (Table 2). A decision to proceed with neonatal $\mathrm{MC}$ requires a thorough discussion on the pros and cons of the procedure. This would allow parents contemplating a MC to make a well-informed choice. Given the socio-economic, educational status and health demographics of our population, universal neonatal circumcision cannot be justified based on the current evidence available.

\section{References}

1. American Academy of Pediatrics: Male Circumcision. Pediatrics 2012: peds.20121990.

2. Guyatt GH, Oxman AD, Vist GE, et al. GRADE: an emerging consensus on 
rating quality of evidence and strength of recommendations. BMJ 2008; 336: 924-6.

3. Babu R, Harrison SK and Hutton KAR: Ballooning of the foreskin and physiological phimosis: is there any objective evidence of obstructed voiding? BJU Int. 2004; 94: 384-387.

4. McGregor TB, Pike JG and Leonard MP: Pathologic and physiologic phimosis: approach to the phimotic foreskin. Can. Fam. Physician Médecin Fam. Can. 2007; 53: 445-448.

5. Liu J, Yang J, Chen Y, et al: Is steroids therapy effective in treating phimosis? A meta-analysis. Int. Urol. Nephrol. 2016; 48: 335-342.

6. Letendre J, Barrieras D, Franc-Guimond J, et al: Topical triamcinolone for persistent phimosis. J. Urol. 2009; 182: 1759-1763.

7. Pileggi $\mathrm{F}$ de $\mathrm{O}$ and Vicente YAMVA: Phimotic ring topical corticoid cream $(0.1 \%$ mometasone furoate) treatment in children. J. Pediatr. Surg. 2007; 42: 1749-1752.

8. Lund L, Wai KH, Mui LM, et al: An 18-month follow-up study after randomized treatment of phimosis in boys with topical steroid versus placebo. Scand. J. Urol. Nephrol. 2005; 39: 78-81.

9. Nobre YD, Freitas RG, Felizardo MJ, et al: To circ or not to circ: clinical and pharmacoeconomic outcomes of a prospective trial of topical steroid versus primary circumcision. Int. Braz J Urol Off. J. Braz. Soc. Urol. 2010; 36: 75-85.

10. Yang SSD, Tsai YC, Wu CC, et al: Highly potent and moderately potent topical steroids are effective in treating phimosis: a prospective randomized study. J. Urol. 2005; 173: 1361-1363.

11. Golubovic Z, Milanovic D, Vukadinovic V, et al: The conservative treatment of phimosis in boys. Br. J. Urol. 1996; 78: 786-788.

12. Winberg J, Andersen HJ, Bergström T, et al: Epidemiology of symptomatic urinary tract infection in childhood. Acta Paediatr. Scand. Suppl. 1974: 1-20.

13. Panaretto KS, Craig JC, Knight JF, et al. Risk factors for recurrent urinary tract infection in preschool children. J Paediatr Child Health 1999; 35:454-9.

14. Shaikh N, Morone NE, Bost JE, et al: Prevalence of urinary tract infection in childhood: a meta-analysis. Pediatr. Infect. Dis. J. 2008; 27: 302-308.

15. Shaikh N, Morone NE, Lopez J, et al: Does this child have a urinary tract infection? JAMA 2007; 298: 2895-2904.

16. Singh-Grewal D, Macdessi J and Craig J: Circumcision for the prevention of urinary tract infection in boys: a systematic review of randomised trials and observational studies. Arch. Dis. Child. 2005; 90: 853-858.

17. Nayir A: Circumcision for the prevention of significant bacteriuria in boys. Pediatr. Nephrol. Berl. Ger. 2001; 16: 1129-1134.

18. Morris BJ: Circumcision and Lifetime Risk of Urinary Tract Infection: A Systematic Review and Meta-Analysis. 189: 2118-2124.

19. Zorc JJ, Levine DA, Platt SL, et al: Clinical and demographic factors associated with urinary tract infection in young febrile infants. Pediatrics 2005; 116: 644-648.

20. To T, Agha M, Dick PT, et al: Cohort study on circumcision of newborn boys and subsequent risk of urinary-tract infection. Lancet Lond. Engl. 1998; 352: 18131816. 
21. Craig JC, Knight JF, Sureshkumar P, et al: Effect of circumcision on incidence of urinary tract infection in preschool boys. J. Pediatr. 1996; 128: 23-27.

22. Morris B, Wiswell T. Circumcision and lifetime risk of urinary tract infection: A systematic review and meta-analysis. J Urol 2013; 189: 2118-24.

23. Alsaywid BS, Saleh H, Deshpande A, et al: High grade primary vesicoureteral reflux in boys: long-term results of a prospective cohort study. J. Urol. 2010; 184: 1598-1603.

24. Kwak C, Oh S-J, Lee A, et al: Effect of circumcision on urinary tract infection after successful antireflux surgery. BJU Int. 2004; 94: 627-629.

25. Gücük A, Burgu B, Gökçe İ, et al: Do antibiotic prophylaxis and/or circumcision change periurethral uropathogen colonization and urinary tract infection rates in boys with VUR? J. Pediatr. Urol. 2013; 9: 1131-1136.

26. Mukherjee S, Joshi A, Carroll D, et al: What is the effect of circumcision on risk of urinary tract infection in boys with posterior urethral valves? J. Pediatr. Surg. 2009; 44: 417-421.

27. Zareba P, Lorenzo AJ and Braga LH: Risk factors for febrile urinary tract infection in infants with prenatal hydronephrosis: comprehensive single center analysis. J. Urol. 2014; 191: 1614-1618.

28. Infectious Disease Prevention and Control: Estimates of HIV Prevalence and Incidence in Canada, 2011h. http://webqa.phac-aspc.gc.ca/aidssida/publication/survreport/estimat2011-eng.php

29. Bailey RC, Moses S, Parker CB, et al: Male circumcision for HIV prevention in young men in Kisumu, Kenya: a randomised controlled trial. The Lancet 2007; 369: 643-656.

30. Gray RH, Kigozi G, Serwadda D, et al: Male circumcision for HIV prevention in men in Rakai, Uganda: a randomised trial. The Lancet 2007; 369: 657-666.

31. Auvert B, Taljaard D, Lagarde E, et al: Randomized, Controlled Intervention Trial of Male Circumcision for Reduction of HIV Infection Risk: The ANRS 1265 Trial. PLoS Med. 2005; 2. Available at http://www.ncbi.nlm.nih.gov/pmc/articles/PMC1262556/, accessed January 13, 2016.

32. Mehta SD, Krieger JN, Agot K, et al: Circumcision and Reduced Risk of SelfReported Penile Coital Injuries: Results from a Randomized Controlled Trial in Kisumu, Kenya. J. Urol. 2010; 184: 203-209.

33. Soto-Ramirez LE, Renjifo B, McLane MF, et al: HIV-1 Langerhans' Cell Tropism Associated with Heterosexual Transmission of HIV. Science 1996; 271: 12911293.

34. McCoombe SG and Short RV: Potential HIV-1 target cells in the human penis: AIDS 2006; 20: 1491-1495.

35. Weiss HA, Quigley MA, Hayes RJ. Male circumcision and risk of HIV infection in sub-Saharan Africa: a systematic review and meta-analysis. AIDS 2000; 14 : 2361-70.

36. Siegfried N, Muller M, Deeks JJ et al. Male circumcision for prevention of heterosexual acquisition of HIV in men (review). The Cochrane Library 2009; 4:1-40. 
37. Wiysonge CS, Kongnyuy EJ, Shey M, et al: Male circumcision for prevention of homosexual acquisition of HIV in men. In: Cochrane Database of Systematic Reviews. John Wiley \& Sons, Ltd 2011. Available at: http://onlinelibrary.wiley.com/doi/10.1002/14651858.CD007496.pub2/abstract, accessed January 12, 2016.

38. Millett GA, Flores SA, Marks G, et al. Circumcision status and risk of HIV and sexually transmitted infections among men who have sex with men: a metaanalysis. JAMA 2008; 300: 1674-84.

39. Wawer MJ, Makumbi F, Kigozi G, et al: Randomized Trial of Male Circumcision in HIV-infected Men: Effects on HIV Transmission to Female Partners, Rakai, Uganda. Lancet 2009; 374: 229-237.

40. Weiss HA, Hankins CA and Dickson K: Male circumcision and risk of HIV infection in women: a systematic review and meta-analysis. Lancet Infect. Dis. 2009; 9: 669-677.

41. Gray R, Kigorzi G, Kong X et al. The effectiveness of male circumcision for HIV prevention and effects on risk behaviors in a posttrial follow up study. AIDS 2012; 5:609-15.

42. Eaton L, Cain D, Agrawal A et al. The influence of male circumcision for HIV prevention on sexual behavior among traditionally circumcised men in Cape Town, South Africa. Int J STD AIDS 2011; 22:6-674-9

43. Larke N, Thomas SL, Silva I dos S, et al: Male Circumcision and Human Papillomavirus Infection in Men: A Systematic Review and Meta-Analysis. J. Infect. Dis. 2011; 204: 1375-1390.

44. Albero G, Castellsagué $\mathrm{X}$, Lin H-Y, et al: Male circumcision and the incidence and clearance of genital human papillomavirus (HPV) infection in men: the HPV Infection in men (HIM) cohort study. BMC Infect. Dis. 2014; 14: 75.

45. Wawer MJ, Tobian AAR, Kigozi G, et al: Effect of circumcision of HIV-negative men on transmission of human papillomavirus to HIV-negative women: a randomised trial in Rakai, Uganda. Lancet Lond. Engl. 2011; 377: 209-218.

46. Tobian AAR, Kong X, Wawer MJ, et al: The Effect of Circumcision of HIVInfected Men on Human Papillomavirus Infection in Female Partners: Analyses Using Data from a Randomized Trial in Rakai, Uganda. Lancet Infect. Dis. 2011; 11: 604-612.

47. Government of Canada PHA of C: Update On Human Papillomavirus (HPV) Vaccines - Canada Communicable Disease Report Monthly - Public Health Agency of Canada. 2012. Available at: http://www.phac-aspc.gc.ca/publicat/ccdrrmtc/12vol38/acs-dcc-1/index-eng.php, accessed June 19, 2016.

48. Winer RL, Hughes JP, Feng Q, et al: Condom use and the risk of genital human papillomavirus infection in young women. N. Engl. J. Med. 2006; 354: 26452654.

49. Mehta SD, Moses S, Agot K, et al: Adult Male Circumcision Does Not Reduce Risk of Incident Neisseria gonorrhoeae, Chlamydia trachomatis, and Trichomonas vaginalis: Results from a Randomized Controlled Trial in Kenya. J. Infect. Dis. 2009; 200: 370-378. 
50. Sobngwi-Tambekou J, Taljaard D, Nieuwoudt M, et al: Male circumcision and Neisseria gonorrhoeae, Chlamydia trachomatis and Trichomonas vaginalis: observations after a randomised controlled trial for HIV prevention. Sex. Transm. Infect. 2009; 85: 116-120.

51. Weiss HA, Thomas SL, Munabi SK, et al: Male circumcision and risk of syphilis, chancroid, and genital herpes: a systematic review and meta-analysis. Sex. Transm. Infect. 2006; 82: 101-110.

52. Seña AC, Miller WC, Hobbs MM, et al: Trichomonas vaginalis infection in male sexual partners: implications for diagnosis, treatment, and prevention. Clin. Infect. Dis. Off. Publ. Infect. Dis. Soc. Am. 2007; 44: 13-22.

53. Turner AN, Morrison CS, Padian NS, et al: Male circumcision and women's risk of incident chlamydial, gonococcal and trichomonal infections. Sex. Transm. Dis. 2008; 35: 689-695.

54. Tobian A, Quinn T. Herpes simplex virus type 2 and syphilis infections with HIV: an evolving synergy in transmission and prevention. Curr Opin HIV AIDS 2009; 4:294- 99.

55. Powers KA, Poole C, Pettifor AE, et al. Rethinking the heterosexual infectivity of HIV-1: a systematic review and meta-analysis. Lancet Infect Dis 2008; 8: 553-63.

56. Freeman EE, Weiss HA, Glynn JR, et al: Herpes simplex virus 2 infection increases HIV acquisition in men and women: systematic review and meta-analysis of longitudinal studies. AIDS Lond. Engl. 2006; 20: 73-83.

57. Tobian AAR, Charvat B, Ssempijja V, et al: Factors Associated with the Prevalence and Incidence of Herpes Simplex Virus Type 2 Infection among Men in Rakai, Uganda. J. Infect. Dis. 2009; 199: 945-949.

58. Tobian A, Serwadda D, Quinn T, et al. Male circumcision for the prevention of HSV-2 and HPV infections and syphilis. N Engl J Med 2009; 13: 1298-1309

59. Sobngwi-Tambekou J, Taljaard D, Lissouba P, et al. Effect of HSV-2 Serostatus on acquisition of HIV by young men: results of a longitudinal study in Orange Farm, South Africa. J Infect Dis 2009; 1: 958-63.

60. Mehta S, Moses S, Parker C et al. Circumcision status and incident herpes simplex virus type 2 infection, genital ulcer disease, and HIV infection. AIDS 2012; 26: 1141-49.

61. Millett GA, Flores SA, Marks G, et al: Circumcision status and risk of HIV and sexually transmitted infections among men who have sex with men: A metaanalysis. JAMA 2008; 300: 1674-1684.

62. Gray RH, Kigozi G, Serwadda D, et al: The effects of male circumcision on female partner's genital tract symptoms and vaginal infections in a randomized trial in Rakai, Uganda. Am. J. Obstet. Gynecol. 2009; 200: 42.e1-42.e7.

63. Tobian AAR, Kigozi G, Redd AD, et al: Male Circumcision and Herpes Simplex Virus Type 2 Infection in Female Partners: A Randomized Trial in Rakai, Uganda. J. Infect. Dis. 2012; 205: 486-490.

64. Larke NL, Thomas SL, dos Santos Silva I, et al: Male circumcision and penile cancer: a systematic review and meta-analysis. Cancer Causes Control CCC 2011; 22: 1097-1110. 
65. Tsen HF, Morgenstern H, Mack T, et al: Risk factors for penile cancer: results of a population-based case-control study in Los Angeles County (United States). Cancer Causes Control CCC 2001; 12: 267-277.

66. Madsen BS, van den Brule AJC, Jensen HL, et al: Risk factors for squamous cell carcinoma of the penis--population-based case-control study in Denmark. Cancer Epidemiol. Biomark. Prev. Publ. Am. Assoc. Cancer Res. Cosponsored Am. Soc. Prev. Oncol. 2008; 17: 2683-2691.

67. Daling JR, Madeleine MM, Johnson LG, et al: Penile cancer: importance of circumcision, human papillomavirus and smoking in in situ and invasive disease. Int. J. Cancer 2005; 116: 606-616.

68. Minhas S, Manseck A, Watya, et al. Penile cancer - prevention and premalignant conditions. Urology 2010; 76 (Suppl 2A): S24-35.

69. Wright JL, Lin DW and Stanford JL: Circumcision and the risk of prostate cancer. Cancer 2012; 118: 4437-4443.

70. Spence AR, Rousseau M-C, Karakiewicz PI, et al: Circumcision and prostate cancer: a population-based case-control study in Montréal, Canada. BJU Int. 2014; 114: E90-98.

71. Ewings $\mathrm{P}$ and Bowie C: A case-control study of cancer of the prostate in Somerset and east Devon. Br. J. Cancer 1996; 74: 661-666.

72. Tian Y, Liu W, Wang J-Z, et al: Effects of circumcision on male sexual functions: a systematic review and meta-analysis. Asian J. Androl. 2013; 15: 662-666.

73. Kigozi G, Watya S, Polis CB, et al: The effect of male circumcision on sexual satisfaction and function, results from a randomized trial of male circumcision for human immunodeficiency virus prevention, Rakai, Uganda. BJU Int. 2008; 101: 65-70.

74. Krieger JN, Mehta SD, Bailey RC, et al: Adult male circumcision: effects on sexual function and sexual satisfaction in Kisumu, Kenya. J. Sex. Med. 2008; 5: 2610-2622.

75. Waldinger MD, McIntosh J and Schweitzer DH: A five-nation survey to assess the distribution of the intravaginal ejaculatory latency time among the general male population. J. Sex. Med. 2009; 6: 2888-2895.

76. Mao L, Templeton DJ, Crawford J, et al: Does circumcision make a difference to the sexual experience of gay men? Findings from the Health in Men (HIM) cohort. J. Sex. Med. 2008; 5: 2557-2561.

77. Kenet G, Chan AKC, Soucie JM, et al. Bleeding disorders in neonates. Haemophilia 2010; 16:168-75.

78. Brady-Fryer B, Wiebe $\mathrm{N}$ and Lander JA: Pain relief for neonatal circumcision. Cochrane Database Syst. Rev. 2004: CD004217.

79. Lehr VT and Taddio A: Topical anesthesia in neonates: clinical practices and practical considerations. Semin. Perinatol. 2007; 31: 323-329.

80. Stevens B, Yamada J, Lee GY, et al: Sucrose for analgesia in newborn infants undergoing painful procedures. Cochrane Database Syst. Rev. 2013: CD001069.

81. Weiss HA, Larke N, Halperin D, et al: Complications of circumcision in male neonates, infants and children: a systematic review. BMC Urol. 2010; 10: 2. 
82. Perera CL, Bridgewater FHG, Thavaneswaran P, et al: Safety and efficacy of nontherapeutic male circumcision: a systematic review. Ann. Fam. Med. 2010; 8: 64-72.

83. Anon: Circumcision policy statement. American Academy of Pediatrics. Task Force on Circumcision. Pediatrics 1999; 103: 686-693.

84. Anon: Neonatal circumcision revisited. Fetus and Newborn Committee, Canadian Paediatric Society. CMAJ Can. Med. Assoc. J. J. Assoc. Medicale Can. 1996; 154: 769-780.

85. Williams N and Kapila L: Complications of circumcision. Br. J. Surg. 1993; 80: 1231-1236.

86. Krill AJ, Palmer LS and Palmer JS: Complications of circumcision. Scientific World Journal 2011; 11: 2458-2468.

87. Joudi M, Fathi $\mathbf{M}$ and Hiradfar M: Incidence of asymptomatic meatal stenosis in children following neonatal circumcision. J. Pediatr. Urol. 2011; 7: 526-528. 
Figures and Tables

Fig 1. Pathological phimosis.

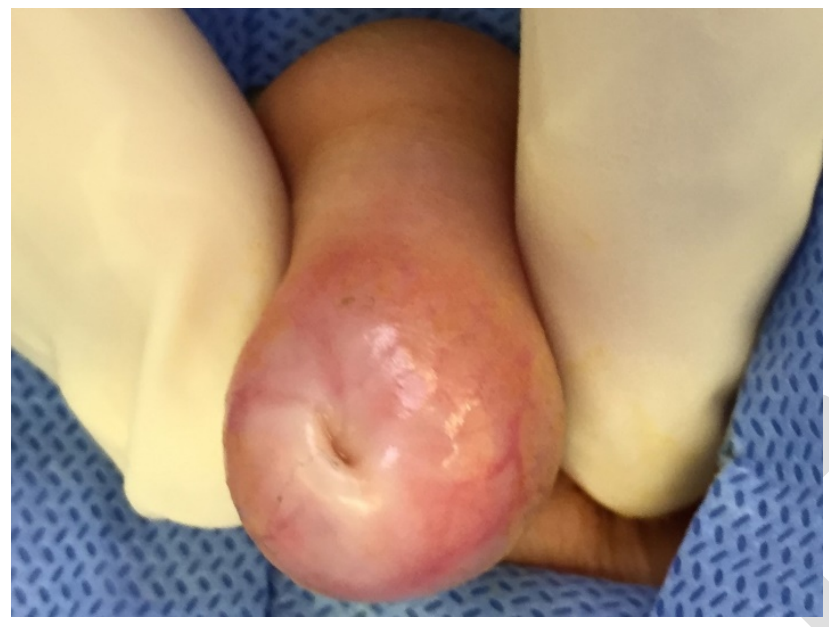

Fig 2. Balano-posthitis.

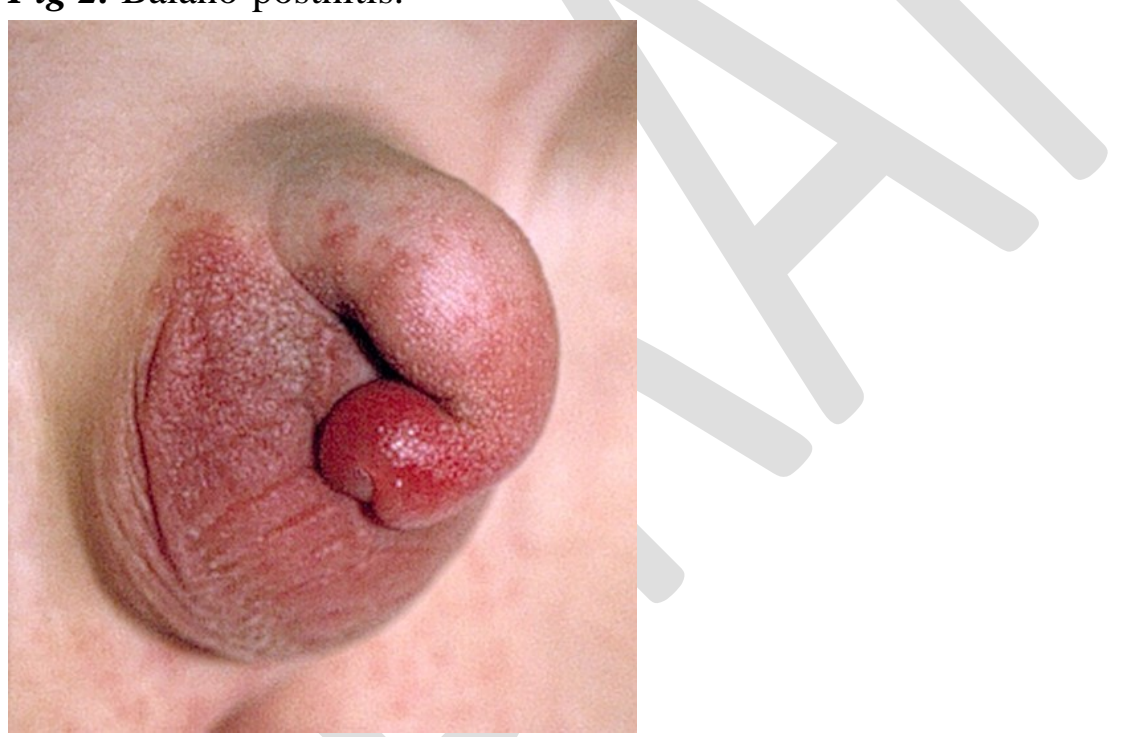


Fig 3. Lichen sclerosus of the foreskin.

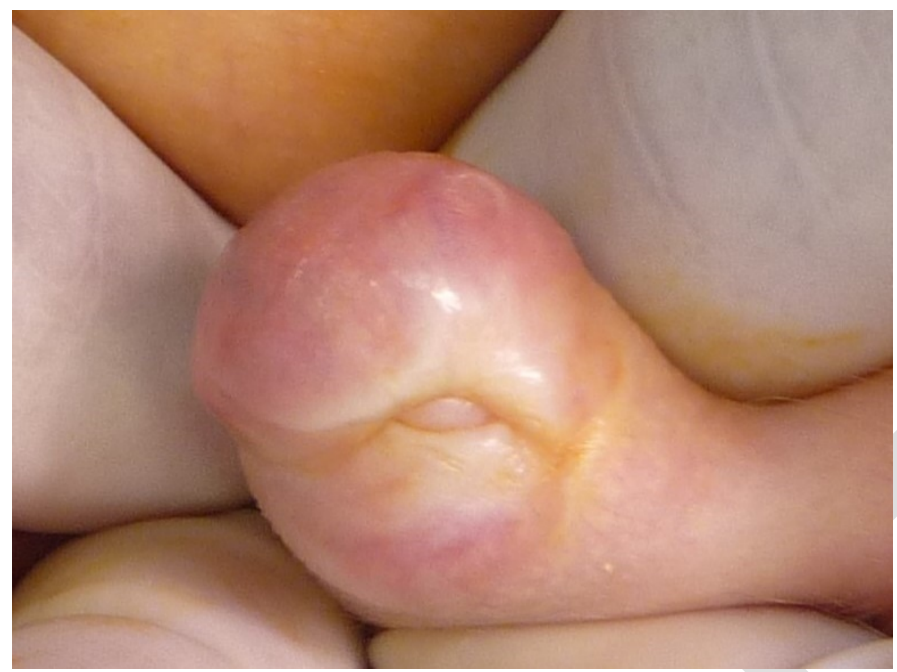

Fig 4. Hypospadias .

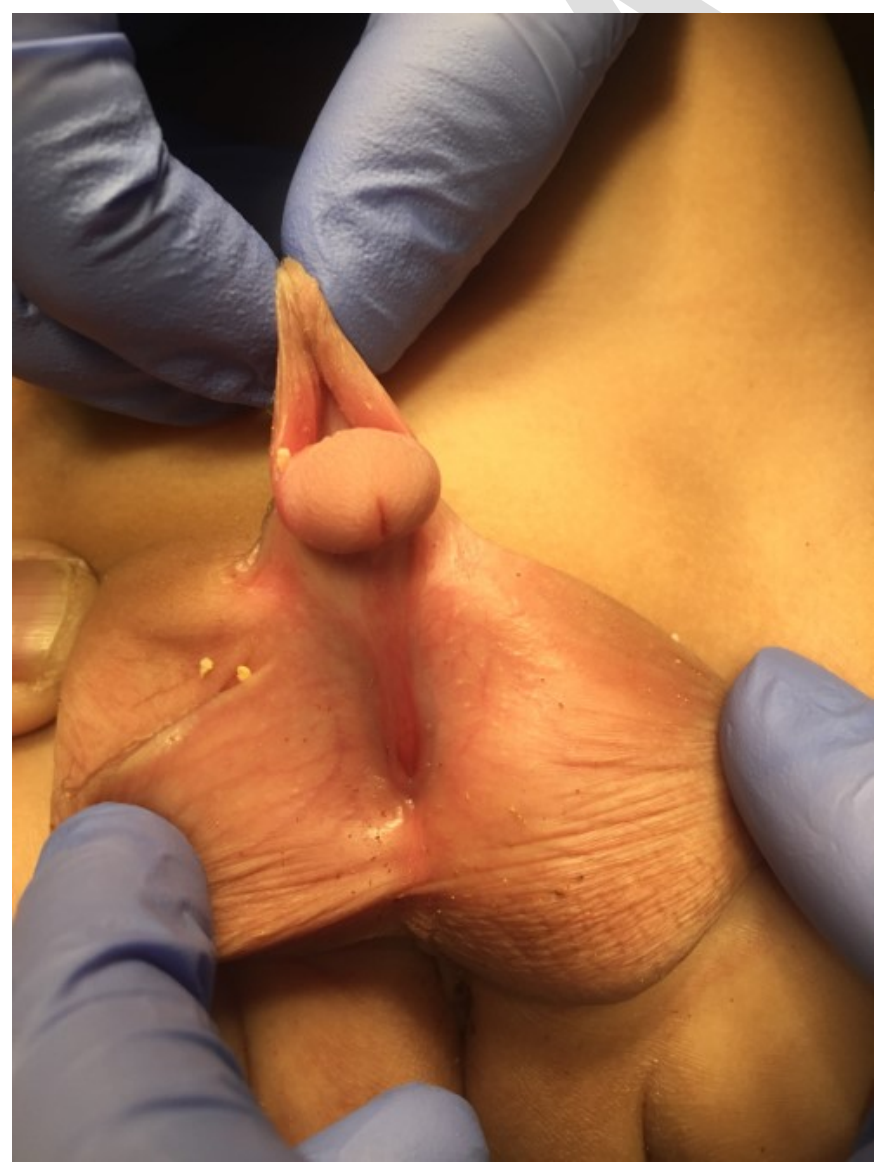


Fig 5. Epispadias.

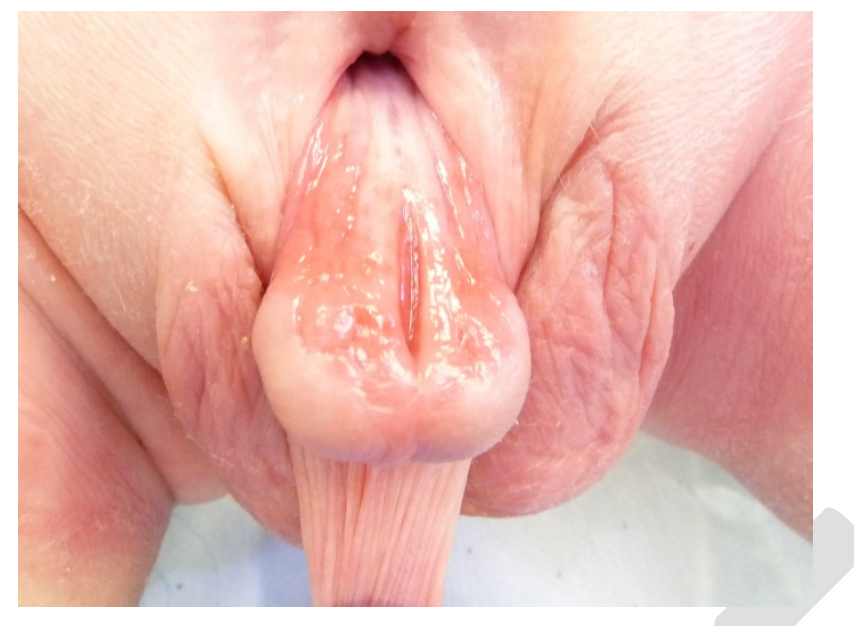

Fig 6. Peno-scrotal webbing.

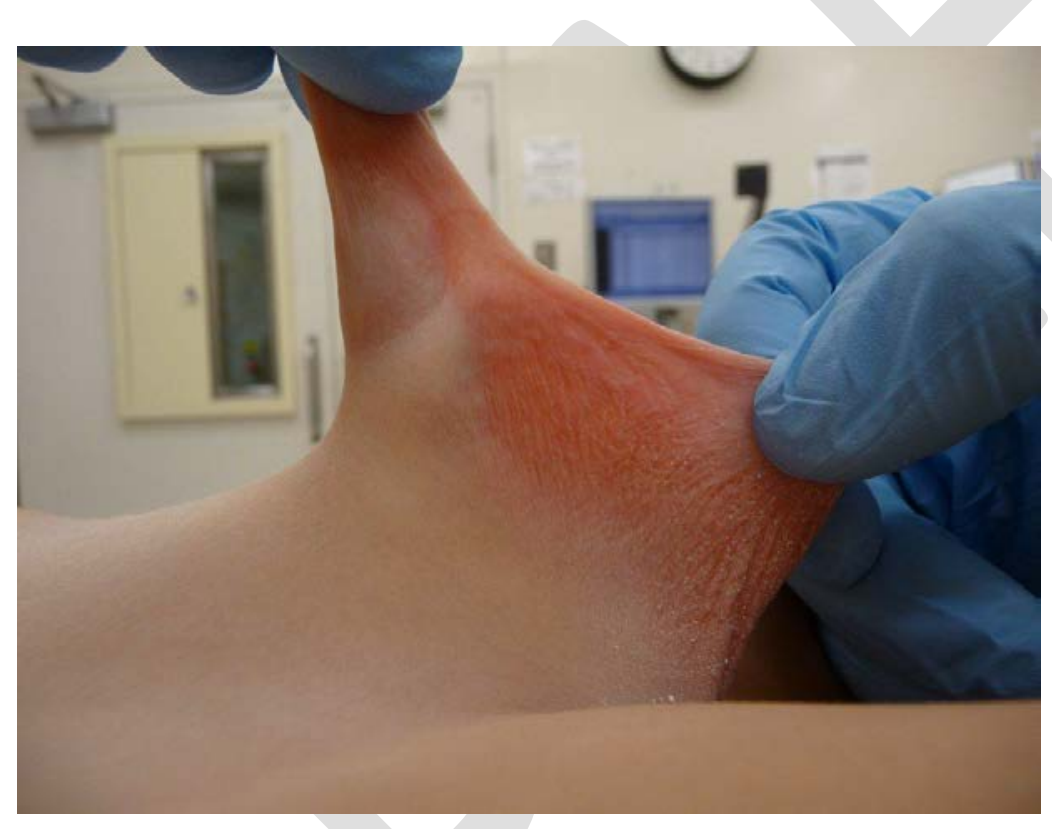


Fig 7. Concealed penis.

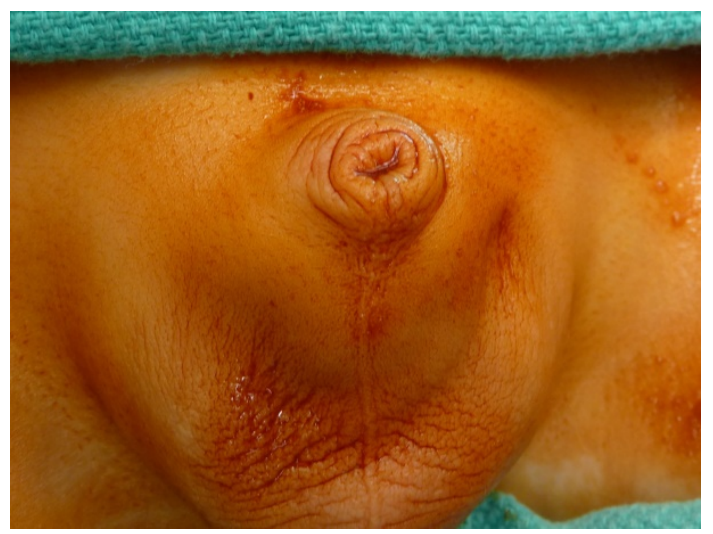

Fig 8. Ventral curvature.

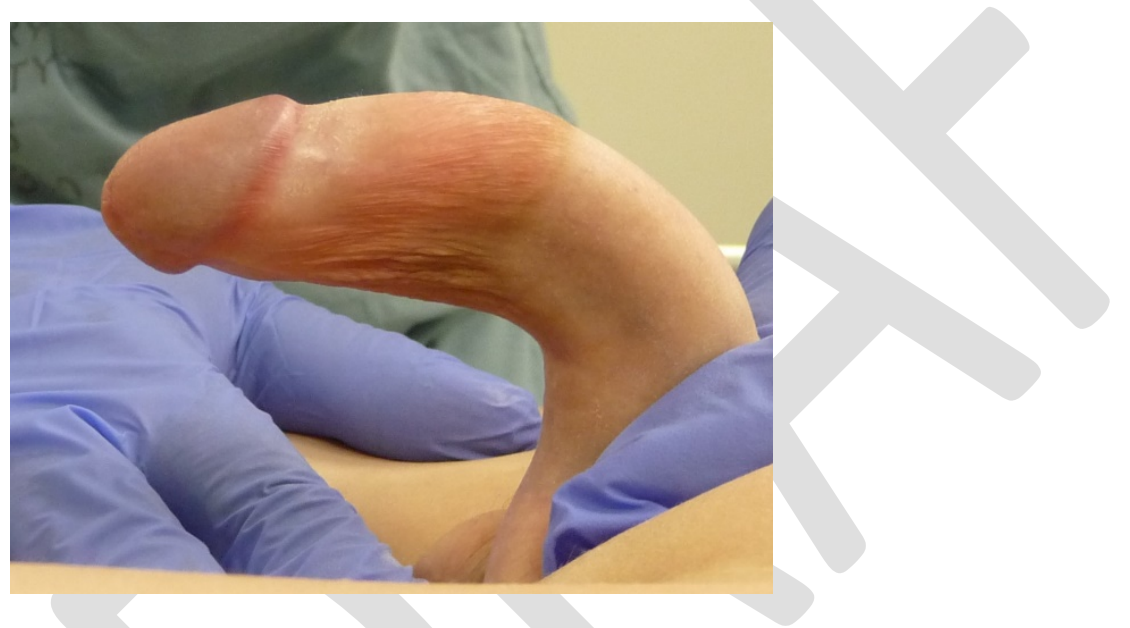

Fig 9. Megameatus intact prepuce hypospadias variant.

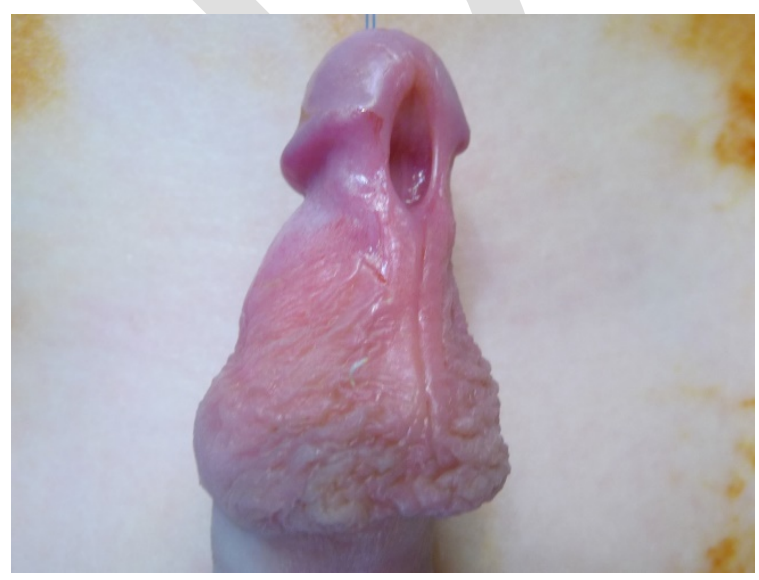




\begin{tabular}{|c|c|c|c|c|c|c|c|c|c|c|c|}
\hline $\begin{array}{l}\text { Study } \\
\text { (location, } \\
\text { time } \\
\text { period) }\end{array}$ & $\begin{array}{c}\text { Allocation } \\
\text { concealment }\end{array}$ & Blinding & $\begin{array}{c}\text { Inclusion } \\
\text { criteria }\end{array}$ & $\mathbf{n}$ & Followup & $\begin{array}{c}\text { Lost to } \\
\text { followup }\end{array}$ & AEs & Outcomes & $\begin{array}{l}\text { ITT RR } \\
(95 \% \text { CI) }\end{array}$ & $\begin{array}{c}\text { As treated } \\
\text { RR } \\
(95 \% \mathrm{CI})\end{array}$ & $\begin{array}{c}\text { Covariate } \\
\text { adjusted } \\
\text { RR }\end{array}$ \\
\hline $\begin{array}{l}\text { Auvert et } \\
\text { al (South } \\
\text { Africa, } \\
2002- \\
2005 \text { ) }\end{array}$ & Partial & $\begin{array}{c}\text { Study } \\
\text { personnel }\end{array}$ & $\begin{array}{c}\text { Male 18-24, } \\
\text { wishing to } \\
\text { be } \\
\text { circumcised }\end{array}$ & 3274 & $\begin{array}{l}\text { Stopped at } \\
63 \% \text { of } \\
\text { total } \\
\text { anticipated } \\
\text { person- } \\
\text { years }\end{array}$ & $\begin{array}{c}251(8 \%) \\
30 \% \text { in } \\
\text { circumcised } \\
\text { and } 33 \% \\
\text { uncircumcised }\end{array}$ & $3.8 \%$ & $\begin{array}{l}\text { Intervention: 20/1546 } \\
\text { Control: 49/1582 }\end{array}$ & $\begin{array}{c}0.42 \\
(0.25-0.70)\end{array}$ & $\begin{array}{c}0.24 \\
(0.14-0.44)\end{array}$ & $\begin{array}{c}0.39 \\
(0.23-0.66)\end{array}$ \\
\hline $\begin{array}{l}\text { Bailey et } \\
\text { al (Kenya, } \\
2002- \\
2006)\end{array}$ & Unclear & $\begin{array}{c}\text { HIV testers } \\
\text { Nurses } \\
\text { counselling } \\
\text { and doing } \\
\text { questionnaires } \\
\text { partially } \\
\text { blinded }\end{array}$ & $\begin{array}{c}\text { HIV- } \\
\text { negative, } \\
\text { 18-24 years }\end{array}$ & 2784 & $\begin{array}{c}\text { Stopped at } \\
87 \% \\
\text { followup }\end{array}$ & $\begin{array}{c}86 \%(1501) \\
\text { completed } 24 \\
\text { month } \\
\text { followup, } \\
\text { overall } \\
\text { 1283/2784 } \\
\text { (46\%) did not } \\
\text { complete trial }\end{array}$ & $1.7 \%$ & $\begin{array}{c}\text { Intervention: 22/1388 } \\
\text { Control: 47/1392 }\end{array}$ & $\begin{array}{c}0.47 \\
(0.28-0.78)\end{array}$ & $\begin{array}{c}0.45 \\
(0.27-0.76)\end{array}$ & $0.44-0.47$ \\
\hline $\begin{array}{l}\text { Gray et al } \\
\text { (Uganda } \\
2002- \\
2006 \text { ) }\end{array}$ & Partial & None specified & $\begin{array}{c}\text { HIV- } \\
\text { negative, } \\
15-49 \text { years }\end{array}$ & 4996 & $\begin{array}{l}\text { Stopped at } \\
72 \% \\
\text { person- } \\
\text { time } \\
\text { accrual }\end{array}$ & $\begin{array}{c}22 \% \text { at } 24 \\
\text { months } \\
\text { followup }\end{array}$ & $8 \%$ & $\begin{array}{c}\text { Intervention: 22/2387 } \\
\text { Control: 45/2430 }\end{array}$ & $\begin{array}{c}0.49 \\
(0.28-0.84)\end{array}$ & $\begin{array}{c}0.45 \\
(0.25-0.78)\end{array}$ & $\begin{array}{c}0.49 \\
(0.29-0.81)\end{array}$ \\
\hline
\end{tabular}

AE: adverse events; CI: confidence interval; ITT: intention-to-treat; RR: relative risk. 


\begin{tabular}{|l|c|c|c|c|c|}
\hline \multicolumn{7}{|l|}{ Table 2. Benefits of circumcision classified by GRADE recommendations } \\
\hline $\begin{array}{l}\text { Clinical } \\
\text { benefit }\end{array}$ & $\begin{array}{c}\text { Direction of } \\
\text { evidence }\end{array}$ & $\begin{array}{c}\text { Amount of } \\
\text { effect }\end{array}$ & $\begin{array}{c}\text { Level of } \\
\text { evidence }\end{array}$ & $\begin{array}{c}\text { GRADE } \\
\text { quality of } \\
\text { evidence }\end{array}$ & $\begin{array}{c}\text { GRADE } \\
\text { strength of } \\
\text { recommendation }\end{array}$ \\
\hline $\begin{array}{l}\text { Decreased } \\
\text { risk of UTI }\end{array}$ & Positive & $0.07-0.23$ & Level 2 & Low quality & Weak \\
\hline $\begin{array}{l}\text { Decreased } \\
\text { risk of HIV }\end{array}$ & Positive & $0.34-0.62$ & Level 1 & High quality & Strong \\
\hline $\begin{array}{l}\text { Decreased } \\
\text { risk of HPV } \\
\text { prevalence }\end{array}$ & Positive & $0.57-0.77$ & Level 1 & $\begin{array}{c}\text { Moderate } \\
\text { quality }\end{array}$ & Weak \\
\hline $\begin{array}{l}\text { Decreased } \\
\text { risk of HPV } \\
\text { incidence }\end{array}$ & Unclear & NS & Level 2 & Low quality & Weak \\
\hline $\begin{array}{l}\text { Decreased } \\
\text { risk of HSV }\end{array}$ & Positive & $0.36-0.91$ & Level 2 & $\begin{array}{c}\text { Moderate } \\
\text { quality }\end{array}$ & Weak \\
\hline $\begin{array}{l}\text { Decreased } \\
\text { risk of penile } \\
\text { cancer }\end{array}$ & Positive & $0.13-0.83$ & Level 2 & Low quality & Weak \\
\hline
\end{tabular}

${ }^{*}$ Concerns related to external validity of data for Canadian population. HPV: human papilloma virus; HSV: herpes simplex virus; UTI: urinary tract infection. 


\begin{tabular}{|c|c|c|c|c|c|}
\hline $\begin{array}{l}\text { Clinical } \\
\text { benefit }\end{array}$ & $\begin{array}{c}\text { Direction of } \\
\text { evidence }\end{array}$ & $\begin{array}{c}\text { Amount of } \\
\text { effect }\end{array}$ & $\begin{array}{l}\text { Level of } \\
\text { evidence }\end{array}$ & $\begin{array}{l}\text { GRADE } \\
\text { quality of } \\
\text { evidence } \\
\end{array}$ & $\begin{array}{c}\text { GRADE } \\
\text { strength of } \\
\text { recommendation }\end{array}$ \\
\hline $\begin{array}{l}\text { Decreased } \\
\text { risk of UTI }\end{array}$ & Positive & $0.07-0.23$ & Level 2 & Low quality & Weak \\
\hline $\begin{array}{l}\text { Decreased } \\
\text { risk of HIV }\end{array}$ & Positive & $0.34-0.62$ & Level 1 & High quality & Strong $^{*}$ \\
\hline $\begin{array}{l}\text { Decreased } \\
\text { risk of HPV } \\
\text { prevalence } \\
\end{array}$ & Positive & $\begin{array}{c}0.57-0.77 \\
\text { Prevalence } \\
\text { rate ratio } \\
\end{array}$ & & $\begin{array}{l}\text { Moderate } \\
\text { quality }\end{array}$ & Weak \\
\hline $\begin{array}{l}\text { Decreased } \\
\text { risk of HPV } \\
\text { incidence }\end{array}$ & Unclear & NS & Level 2 & Low quality & Weak \\
\hline $\begin{array}{l}\text { Decreased } \\
\text { risk of HSV }\end{array}$ & Positive & $0.36-0.91$ & Level 2 & $\begin{array}{c}\text { Moderate } \\
\text { quality }\end{array}$ & Weak \\
\hline $\begin{array}{l}\text { Decreased } \\
\text { risk of } \\
\text { penile } \\
\text { cancer }\end{array}$ & Positive & $0.13-0.83$ & Level 2 & Low quality & Weak \\
\hline
\end{tabular}

${ }^{*}$ Uncertainty related to: 1 ) effects of neonatal circumcision in Canadian setting; 2)

whether circumcision represents a wise use of resources compared to other preventive strategies; 3) the balance of advantages versus risks of circumcision given the uncertainty of circumcision risks. HPV: human papilloma virus; HSV: herpes simplex virus; UTI: urinary tract infection. 
